\title{
Fatigue limit estimation using IR camera
}

\author{
Zuzana Stankovičová ${ }^{1, *}$, Vladimír Dekýš ${ }^{1}$, Milan Uhríčik $^{1}$, Pavol Novák $^{1}$, \\ Bohumir Strnadel ${ }^{2}$ \\ ${ }^{1}$ University of Žilina, Faculty of Mechanical Engineering, Department of Applied Mechanics, Slovak \\ Republic \\ ${ }^{2}$ Center of Advanced Innovation Technologies, VŠB-Technical University Ostrava,Czech Republic
}

\begin{abstract}
Determination of fatigue limit by traditional method is associated with testing of large number of specimens. This is caused by more scatter in test results and therefore a higher amount of tests are needed to generate a statistically reliable trend. The paper presents rapid and reliable estimation of fatigue limit using infrared thermography. By analysing the temperature of the material surface during cyclic loading it is possible to evaluate the dynamic behaviour of a structure and determine the fatigue limit. The method provides reliable results using a very little number of specimens in a very short time compared with traditional method.
\end{abstract}

Keywords: Fatigue limit, Wöhler diagram, infrared camera, thermography

\section{Introduction}

Repeated mechanical, thermal or mechanical-thermal stresses of the material result in a gradual accumulation of damage. This process is known as material fatigue. Material failure due to fatigue can occur only in the presence of microcraks or defects in material. If a static load occurs on a sample, local plasticization and redistribution of stress to the surrounding material does not create a critical condition and material breaks only at higher stresses according to the strength condition. In the case of cyclic loading, if the material comes into the state of local microplasticity, a microcracking occurs. Repeated application of the same loads results in crack propagation up to the fracture [1].

The fatigue limit $\sigma_{C}$ is used as a material resistance against such repeated loading. This quantity is theoretically defined as the minimum stress level below which material is not damaged. It is an experimentally determined value that indicates the stress or plastic strain level at which the material can withstand an infinite number of cycles [2].

\subsection{A traditional approach to fatigue assessment}

By classic approach, the fatigue limit is determined by experimentally compiling the fatigue curve. It is necessary to perform a series of fatigue test at different stress levels into the failure. The numbers of cycles, in which samples are broken, are observed. The fatigue curve is constructed, usually in the coordinate $\sigma-N$ (stress level - number of cycles to

\footnotetext{
* Corresponding author: zuzana.stankovicova@,fstroj.uniza.sk

Reviewers: Wiestawa Piekarska, Ján Vavro
} 
fracture). This task is time-consuming, especially in the case of high-cycle fatigue, where there is more scatter in the results. Therefore more testing is needed to create a statistically reliable trend. The fatigue test for high-cycle fatigue is usually performed in $10^{7}$ cycles and for non-ferrous metals up to $5.10^{8}$ cycles.

The area of high cycle fatigue is characterized by the Wöhler diagram. This area can be characterized by Wöhler's relationship in the alternating cycle:

$$
\sigma_{\max }=\sigma_{f}^{\prime}\left(N_{f}\right)^{b}
$$

where $\sigma_{f}^{\prime}$ is coefficint of the fatigue strength obtained by extrapolating the lifetime curve to first load cycle and $b$ is exponent of fatigue lifespan and its value for metals is moving in the ranfe of -0.05 to -0.12 . These parameters are determined experimentally. In the past two decades, several articles have been published [3-5] related to the use of IR thermography in fatigue tests. Based on the energy emitted from the material and captured by the IR camera during a fatigue test it is possible to determine the fatigue limit and even the whole fatigue curve with a smaller number of samples than the classic fatigue test.

\subsection{Using infrared thermography for fatigue tests}

In one of the first works [6] the authors compared the traditional method for the construction of a fatigue curve with temperature measurements on the outer surface 57 samples, using the same loading frequency for the duration of the test (more than 250 hours of recording). A thorough examination of the recorded data highlighted the important aspects that were then subject to further investigation [4]. If the applied stress was below the fatigue limit, the temperature increase in the warmest place was practically zero. If the value of stress reaches the fatigue limit, the temperature increases during the first part of the test (phase 1), then it remains constant (phase 2) until the short time before the failure, followed by a rapid increase of the temperature until the fracture (phase 3). Fig. 1 shows the given phases during the test.

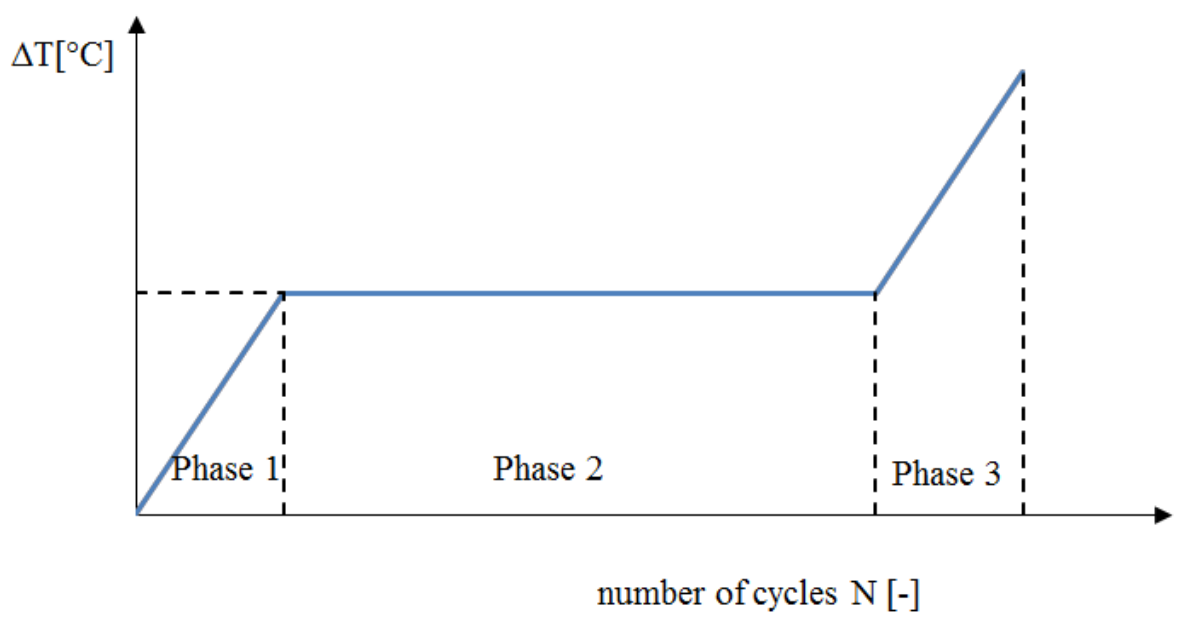

Fig. 1. Phases during the fatigue test [4] 
Analysis of fatigue damage using infrared thermography can be done by evaluating dissipative energy, where heat production correlates with energy dissipation in the material. Luong [5] developed a method for the rapid evaluation of fatigue limit based on the detection of dissipated energy from the material loaded with cyclic loading.

Based on Luong's approach, Bremond and Potet [7] developed the "D-mode" technique. This is digital imaging, which is implemented in the commercially available Altair LI software (module is enable to detect heat generation due to local plastic deformation at various levels of fatigue amplitude). There is minimal energy dissipation for loading under fatigue limit. Under loading greater the fatigue limit a microplastic deformation occurs resulting in a rise in temperature. The test is carried out by gradually increasing the stress level. The dependence of the stress level on the dissipative energy in the form of temperature $T_{D, i}$ is graphically constructed. The voltage at which the temperature increases sharply corresponds to the fatigue limit value obtained from the classical fatigue test [8].

\section{Fatigue limit determination using IR thermography}

Determination of the fatigue limit using infrared thermography was used for cold-rolled material S235J. In the experiment flat bars were used. The shape of the sample and its dimensions are in Fig. 2.

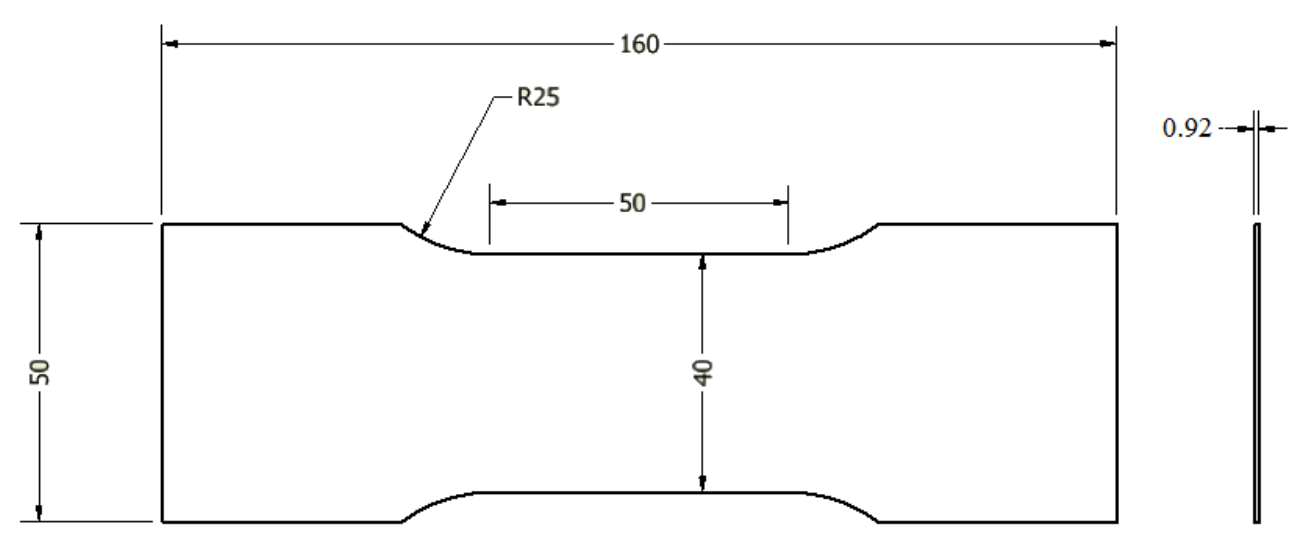

Fig. 2. Sample used in experiment

The test was carried out using a ZWICK Roel Vibrophores Amsler 150 HFP 5100 Resonant Pulsator. The samples were loaded sequentially, with a static and dynamic force value being entered, which are essentially the mean value and the amplitude of the load cycle. Since a thick flat sheet was used for the measurement, an asymmetry $R=0$ was chosen to avoid sample buckling. Table 1 shows the amplitude values of the force and the corresponding stress at three measurements. Some parts of the table are not filled because they have been skipped in these modes, for example due to the properties of the test device. 
Table 1. Amplitude values

\section{Amplitude value of the force[N]}

Amplitude value of the stress [MPa]

\begin{tabular}{rrrrrrrrrrrrrrr}
\hline 1. & 2720 & 2880 & 3040 & 3200 & 3360 & 3520 & 3680 & 3760 & 3840 & 3920 & 4000 & 4160 & 4480 \\
& 74 & 78 & 82 & 87 & 91 & 95 & 100 & 102 & 104 & 106 & 108 & 113 & 121 \\
\hline 2. & 2720 & 2880 & 3040 & 3200 & 3360 & 3520 & 3680 & 3760 & 3840 & 3920 & 4000 & - & - \\
& 74 & 78 & 82 & 87 & 91 & 95 & 100 & 102 & 104 & 106 & 108 & - & - \\
\hline 3. & 2720 & 2880 & 3040 & 3200 & 3360 & 3520 & - & - & 3840 & - & 4000 & 4160 & 4480 \\
& 74 & 78 & 82 & 87 & 91 & 95 & - & - & 104 & - & 108 & 113 & 121 \\
\hline
\end{tabular}

FLIR SC7500 IR camera was used to measure temperature changes. The measurement was used frame frequency $f_{\text {frame }}=383 \mathrm{~Hz}$. A white emission spray was applied to the samples to reduce the reflection from the surroundings (the spray is for LWIR, in our case the spray was designed to homogenize the surface to be measured). The sample was shielded with polystyrene blocks because there was a change of weather during the day, which could affect the measurement. The evaluation was performed in the Altair LI software in the D-module dissipation. The processing was selected for 10 seconds, representing 3830 frames. At each stress level, the measurement was started only after the 10000 cycles that the material had needed to stabilize the temperature. In the thermograms, the area was selected (the same in each measurement) and processed. This processing was carried out for all stress levels on three samples. Subsequently, a graph of the dissipative energy dependence in the form of temperature from the stress level was plotted - Fig. 3 because the change of this energy during the test can be expressed by changing the temperature of the sample.

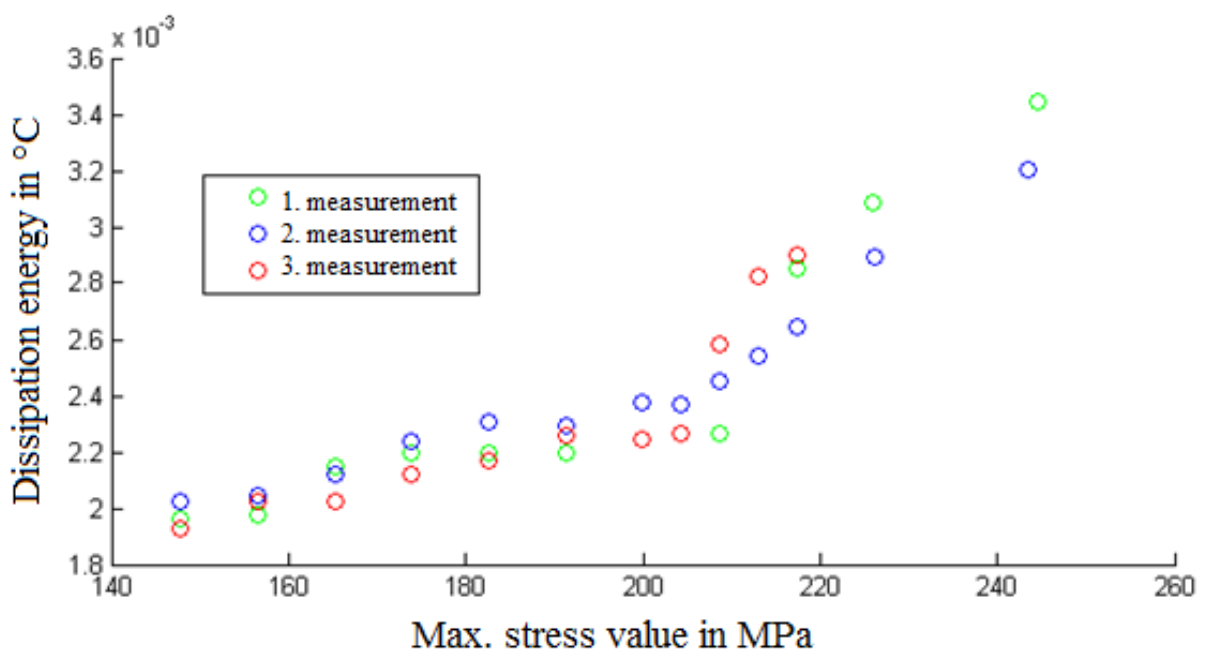

Fig. 3. Results of measurements 
On further processing we decided to average the results of the measured data for each stress level. The resulting graph is in Fig. 4, where there is also a visible break within 200-210 MPa. The points are the order numbers of each load level.

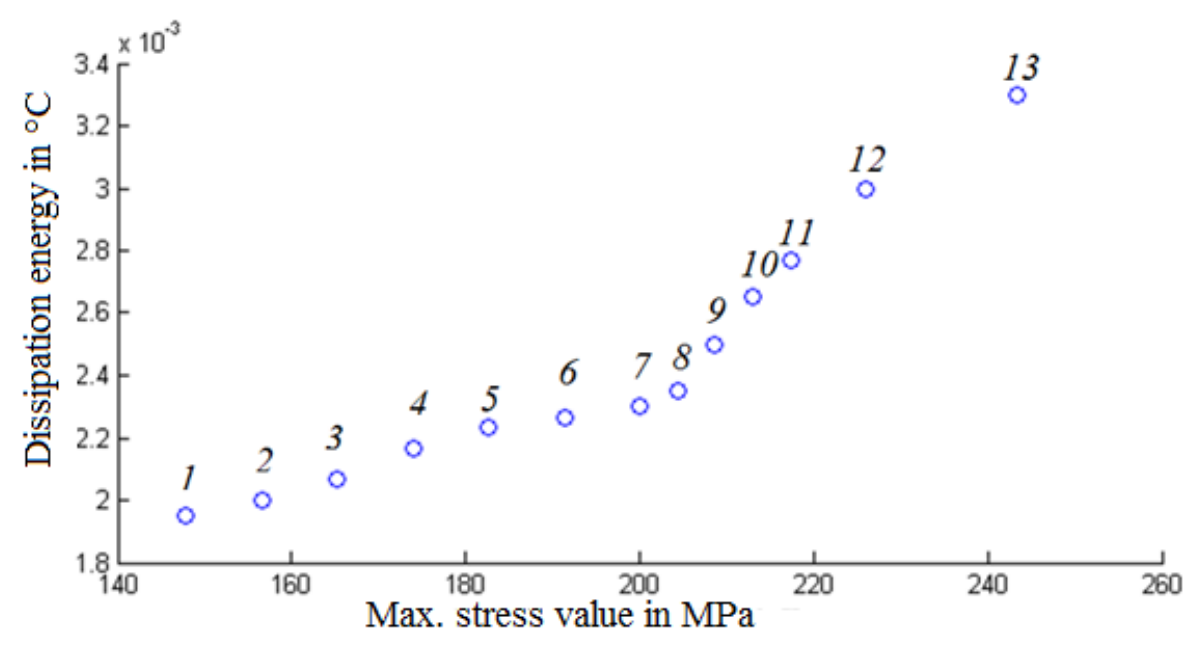

Fig. 4. Results of measurements

The method of slopes was used to evaluate the fatigue limit. For each two points, the slope was calculated from their coordinates. Then a graph of the changes of slopes was plotted, on which an increase in $7^{\text {th }}$ ratio is visible. It is difference between the $7^{\text {th }}$ and $8^{\text {th }}$ slopes, which are points 7, 8 and 9. In the figure 5a is the resulting graph, where the red dot highlights a significant break that indicates a fatigue limit 204.35 MPa. Estimation was corrected using 2 linear regression lines. Each of two groups of points, by which were determined the lines, included red dot. In Fig. $5 \mathrm{~b}$ is the results of the approximation, the intersection of lines corresponds the stress value of $201.54 \mathrm{MPa}$. This corresponds to the level of dissipative energy expressed as a temperature $0.0024^{\circ} \mathrm{C}$.

a)

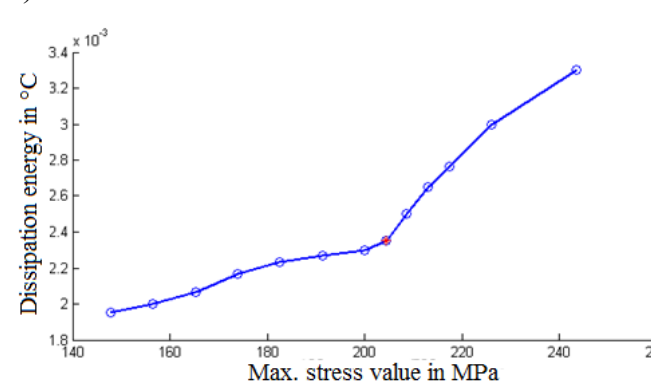

b)

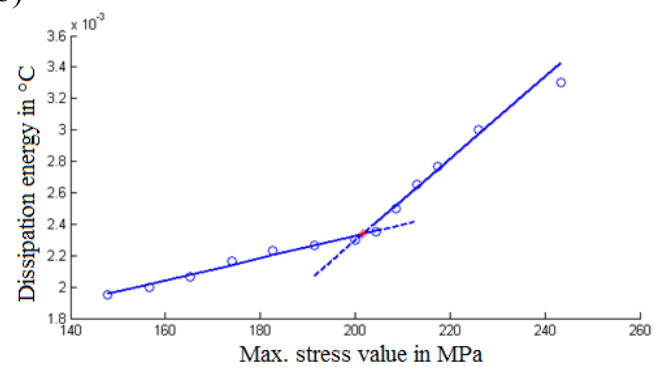

Fig. 5. Results of measurements

Value of fatigue limit from the experimental measurement from literature for steel sheet and material S235J equals to $195 \mathrm{MPa}$ [9]. The difference between the values is close to 4 percent. 


\section{Conclusion}

Paper deals with the application of infrared thermography in fatigue tests. The experiment was performed on a material S235J. For a quick determination of a fatigue limit the evaluation of dissipation energy was used. The measured energy values were processed in the D-module of the Altair LI software in the form of temperature. In total, three measurements were performed in order to average the results. The result of fatigue limit was compared with the experimental measurement of the material from the literature. The difference between the values is close to 4 percent.

This contribution is related to dynamic analysis work $[9,10]$ at the Faculty of Mechanical Engineering, Department of Applied Mechanics, University of Žilina [11-14] and partners $[15,16]$.

This work is supported by the Slovak Research and Development Agency under the contract No. APVV-0736-12 and by KEGA 015ŽU-4/2017 Digital technologies for machine building study programs as a part of strategy "Internet of Things" and VEGA 1/0983/15.

\section{References}

1. G. Fargione et al., Rapid determination of the fatigue curve by the thermographic method. International journal of fatigue 24, 11-19 (2002)

2. A. Puškár, R. Pohl, Dynamická pevnost' a únavová životnost’. (Bratislava, Alfa, 1987)

3. F. Risitano, et al, Determination of the fatigue limit by semi static tests. Cassino, Italy, 13-15 Giungo, ISBN 978-88-9594-36-6 (2011)

4. G. Rosa, A. Risitano, Thermographic methodology for rapid determination of the fatigue limit of materials and mechanical components. Internationl journal of fatigue 22, 65-73 (1999)

5. M. P. Luong, Nondestructive damage evaluation of reinforced concrete structure using infrared thermography. Society of photo-optical instrumentation engineers, Newport Beach, CA, USA, 98-107 (1995)

6. G. Curte et al, Analisi tramite infrarosso termico della "temperatura limite" in prove di fatica. [in Italian] $14^{\text {th }}$ AIAS Italian National Conference, Catania, Italy, 211-20 (1986)

7. P. Bremod, P. Potet, Lock-in thermography: a tool to analyze and locate thermomechanical mechanisms in materials and structures. Proceedings of SPIE 4360, 560, (2001)

8. A. Akai et al., Relationship between dissipated energy and fatigue limit for austenitic stainless steel. $15^{\text {th }}$ International conference on experimental mechanics, Portugal, (2001)

9. www.totalmateria.com

10. F. Novy, M. Cincala, P. Kopas, O. Bokuvka, Mechanisms of high-strength structural materials fatigue failure in ultra-wide life region. Materials Science and Engineering A-Structural Materials Properties Microstructure and Processing 462 (1-2), 189-192 (2007)

11. G. Nicoletto, O. Bokuvka, L. Collini, P. Kopas, Fatigue resistance in a very high-cycle regime. Transaction of FAMENA 29 (1), 9-16 (2005) 
12. M. Zmindak, P. Pastorek, Finite element analysis of cohesion between reinforced concrete beam and polymer lamella reinforced by carbon fibers. Procedia engineering 177, 582-589 (2017)

13. P. Kopas, L. Jakubovičová, M. Vaško, M. Handrik, Fatigue Resistance of Reinforcing Steel Bars. Procedia Engineering 136, 193-197 (2016)

14. M. Handrik, P. Kopas, V. Baniari, M. Vaško, M. Sága, Analysis of stress and strain of fatigue specimens localised in the cross-sectional area of the gauge section testing on bi-axial fatigue machine loaded in the high-cycle fatigue region. Procedia Engineering 177, 516-519 (2017)

15. B. Strnadel, P. Ferfecki, P. Židlík, Statistical characteristics of fracture surfaces in $X 70$ steel DWTT samples. Engineering Fracture Mechanics 112, 1-13 (2013)

16. J. Xiong, P. Guo, Y. Cai, B. Strnadel, J. Brumek, Y. He, H. Gu, Structural, magnetic and nanomechanical properties in Ni-doped AlN films. Journal of Alloys and Compounds Volume 606, 55-60 (2014) 